\title{
Evaluating the Abrasivity of a Nanosized Eggshell- Titanium Dioxide on Tooth Enamel Using Atomic Force Microscopy
}

\author{
Stanley Chibuzor Onwubu ${ }^{1}$ Phumlane Selby Mdluli² \\ Rookmoney Thakur ${ }^{5}$ \\ ${ }^{1}$ Department of Dental Sciences, Durban University of Technology \\ (DUT), Durban, South Africa \\ 2Department of Chemistry, Durban University of Technology (DUT), \\ Durban, South Africa \\ ${ }^{3}$ Discipline of Dentistry, University of KwaZulu-Natal (UKZN), \\ Durban, South Africa \\ ${ }^{4}$ DST/Mintek Nanotechnology Innovation Centre, Advanced \\ Materials Division, Mintek, Randburg, Johannesburg, \\ South Africa \\ 5 Public Management and Economics, Durban University of \\ Technology (DUT), Durban, South Africa
}

Eur J Dent:2020;14:598-604
Shenuka Singh ${ }^{3} \quad$ Sanele Nyembe ${ }^{4}$

\begin{abstract}
Address for correspondence Stanley Chibuzor Onwubu, PhD, Department of Dental Sciences, Durban University of Technology (DUT), Durban, South Africa (e-mail: 21445599@dut4life.ac.za).
\end{abstract}

\begin{abstract}
Keywords

- abrasivity

- enamel

- toothpaste

- Atomic Force

Microscope

Objectives This study aimed to evaluate nanosized eggshell-titanium dioxide $\left(\mathrm{EB} @ \mathrm{TiO}_{2}\right)$ abrasiveness in comparison with calcium carbonate and hydrated silicacontaining toothpaste.

Material and Methods Thirty-five bovine tooth enamels were prepared, and specimens randomly assigned to a sample group of five $(n=7)$, namely, Colgate regular, Colgate pro-relief, Sensodyne rapid relief, Sensodyne repair, and EB@TiO 2 . Half of the enamel surface was brushed with each respective sample group, while the other half was covered with a tap.

Statistical Analysis The mean roughness value ( $R a)$ of the brushed and covered halves were measured using an atomic force microscope (AFM). To assess the surface morphology and changes, a scanning electron microscope (SEM) was performed. Using pair sample test and ANOVA, the Ra for the entire specimens were analyzed. A Bonferroni correction was used to identify the mean differences among the five groups $(\alpha=.05)$.

Results The findings from this analysis show that all the tested toothpaste abraded the enamel significantly $(p<0.05)$. The abrasive value contained in toothpaste comprising calcium carbonate was lower than the silica toothpaste hydrated.

Conclusion Overall, Colgate regular had the lowest toothpaste abrasivity, followed by $\mathrm{EB} @ \mathrm{TiO}_{2}$, while Sensodyne rapid relief had the most enamel wear. The prominent feature of this study suggests that $\mathrm{EB} @ \mathrm{TiO}_{2}$ is suitable for oral use, as its abrasivity is comparable with calcium carbonate-containing toothpaste.
\end{abstract}

DOI https://doi.org/

10.1055/s-0040-1714172

ISSN 1305-7456.
License terms

() (1) $\ominus \circledast$ 


\section{Introduction}

The oral health of the general population worldwide has improved dramatically in the last decade. Part of this change may be due to the routine use of toothpaste as an important oral product for home care. ${ }^{1}$ Traditionally, toothpaste comes in gel or paste form that is often utilized with a toothbrush for improved oral hygiene, well-being, and aesthetics. ${ }^{2}$ The creation of toothpaste formed as a result of the use of powdered ox hooves, myrrh, eggshell, and pumice, to remove dust from teeth-to more complex ingredient-after the introduction by the Egyptians around the year 3000-5000 BC. ${ }^{2}$ Modern toothpaste has been manipulated decades ago to deliver physical and chemical mediated benefits, particularly to remove calculus and extrinsic stain, prevent supragingival plaque and caries, as well as for dentine hypersensitivity treatment. ${ }^{3,4}$

Importantly, modern toothpaste contains abrasives that support tooth cleaning by whitening the enamel, stimulating fresh breath, and optimizing coloration for their visual appeal. ${ }^{2}$ According to the aforementioned author, abrasives remain a customary toothpaste excipient and a secondary contributor to toothpaste rheology. ${ }^{2}$ Ideally, particles of abrasive are tougher compared with stain although milder than sound enamel. This means that stains can be removed effectively without potential severe impairment of the tooth surface. ${ }^{5}$ This particularly is important since undesirable tooth wear may be caused by abrading the tooth surface by enormous abrasive material. ${ }^{6}$ According to Lippert, ${ }^{2}$ several important parameters can affect the abrasive cleaning process, and these parameters might include the following: particle toughness; shape; size and its allocation; in addition to its particle concentration and burden exerted when brushing. Therefore, the crucial target of toothpaste manufacturing companies is to refine and optimize this formulation in an effort to boost the cosmetic and oral health benefits. ${ }^{7}$ In view of these, manufacturers offer abrasive action use silica, calcium carbonate, alumina oxide, sodium metaphosphate, dicalcium phosphate, perlite, sodium bicarbonate, nanohydroxyapatite, and calcium pyrophosphate, among others. ${ }^{2,6}$ However, Field ${ }^{8}$ was concerned about the possibility of different abrasion characteristics, resulting from the action of these materials, although they may be complex and share chemically identical components.

In fact, previous studies ${ }^{9,10}$ show that toothpaste abrasivity can pose substantial consequences on the abrasion rate relative to the brush's structure. In addition, modern toothpaste has different abrasivity values due to its complex formulation. ${ }^{8}$ Consequently, there is a need to understand their clinical applications vis-à-vis effectiveness and safety concerns, in order to avoid surface damage of the enamel and dentine. ${ }^{6,11}$ The knowledge is vital to reduce the negative impact of toothpaste abrasiveness on exposed cementum and dentine surfaces, ${ }^{12}$ and reopening of the occlusion of dentine tubules during brushing procedure, ${ }^{13}$ resulting in dentine loss. ${ }^{14}$

Besides, it is cautious to note that the abrasivity of toothpaste products can induce tooth wear, which could cause dentine hypersensitivity, ascending from the exposed dentine.
This is of concern due to the resilient association between the toothpaste abrasiveness, brushing of tooth, occurrence of caries, acute trauma, periodontal disease, and dentine abrasion. ${ }^{8,15}$ Therefore, to clean teeth effectually, toothpaste does not have to be exceedingly abrasive. ${ }^{12}$ Hence, ideal toothpaste should offer the lowest abrasion intensity to achieve a maximum cleaning of tooth surfaces. ${ }^{6,12}$ Fundamentally, the "quest" for most manufacturers of toothpaste and abrasives is to produce toothpastes that clean effectively without causing any abrasion on dental hard tissues. ${ }^{2}$

In recent years, considerable attention has been paid to the usage of powders from eggshells as a result of its relatively low-abrasivity. Evidence has shown that a dental abrasive material originating from eggshells are good as polishers for dental acrylics. ${ }^{16}$ In addition, the ultrafine powder is produced from eggshells of particle size between $0.1 \mu \mathrm{m}$ to $10 \mathrm{~nm}$ which are suitable in cosmetics and toothpaste manufacturing. ${ }^{17}$ Although the relative enamel abrasivity (REA) and/or relative dentin abrasivity (RDA) is International Organization for Standardization (ISO 11609) certified $^{17}$ as a standard test for determination of desensitizing paste abrasiveness, ${ }^{18}$ the procedure, however, incorporates a radiation-based technique requiring regulatory clearance to use isotope. ${ }^{6}$ Consequently, an alternative technique, such as the use profilometry analysis to assess the abrasiveness of toothpaste was suggested by ISO 11609. Another useful device, like the profilometry, is the atomic force microscope (AFM) that has attracted increasing in interest in dental hard tissue studies. ${ }^{19-21}$ AFM is applied widely, obtaining quantitative (roughness value) and qualitative (3D images) dental tissue analysis simultaneously at a very small scale, thereby not only offering a clear perception of the treatments and development of oral disease but also the coating of biomedical devices. ${ }^{22,23}$ This study is aimed at evaluating the abrasivity of new toothpaste formulation containing titanium dioxide $\left(\mathrm{EB} @ \mathrm{TiO}_{2}\right)$ and modified eggshell powder in comparison with commercially available toothpastes using AFM. The null hypothesis considers no significant variation between the

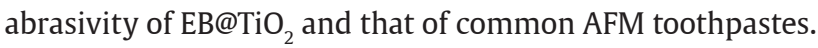

\section{Materials and Methods}

A purchase of Anatase titanium dioxide (CAS Number: 13463677) was made from Sigma-Aldrich in Germany. Four (4) separate brands of toothpaste specifically, a Sensodyne repair, a rapid relief by GlaxoSmithKline, UK, plus Colgate regular, and Colgate pro-relief from Colgate-Palmolive in Poland were purchased from a mall in Durban, South Africa.

\section{Eggshell-Titanium Dioxide (EB@TiO $)_{2}$ ) Preparation}

A composite of eggshell and titanium dioxide were modified in harmony with the method reported by Onwubu et al following two steps. First, a $30 \mathrm{~g}$ measure of the dried eggshell was placed in a 0.51 stainless jar (of $100 \mathrm{~mm}$ inner diameter) jointly with 50 stainless steel balls $(10 \mathrm{~mm}$ diameter) and dry-milled in a planetary ball mill (Retsch PM 100) at 400 revolutions per minute (rpm) for 20 minutes. Using a mechanical sieving shaker (Retsch AS 200 from Germany), 
the owder collected was sieved into a particle size of $\leq 25 \mu \mathrm{m}$. Subsequently, a fine eggshell powder of $20 \mathrm{~g}$ obtained in the first step was modified by the addition $5 \mathrm{~g}$ worth of anatase titanium dioxide $(\leq 15 \mu \mathrm{m})$. The mixture was then ball-milled for 200 minutes to get the eggshell-titanium dioxide composite $\left(\mathrm{EB}_{\mathrm{TTiO}}\right)$. It is worth mentioning that an extensive detail of the size of the particle, its shape, phase, and cytotox-

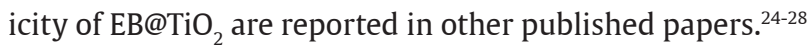

\section{Assessing the Abrasivity of EB@TiO,}

Abrasiveness of EB@TiO 2 on tooth enamel was measured in vitro using a simulated brushing protocol (-Fig. 1). Thirtyfive bovine enamels (measuring $5 \mathrm{~mm} \times 5 \mathrm{~mm} \times 3 \mathrm{~mm}$ ) prepared by partitioning perpendicular to the long axis of the teeth directly below the enamel-dentinal junction using a diamond saw of low-speed under water cooling conditions was obtained. Thereafter, an enamel disc was fixed in a resin (AMT composite, South Africa). A silicone mold (Agar scientific; Silicone rubber mold) was now used to make a mounting base.

Before brushing, the samples were kept in artificial saliva (-Table 1) for 5 minutes to simulate oral condition. One half of the tooth was then protected with aluminum tape. Tooth brushing was perform using a powered $1.5 \mathrm{v}$ alkaline battery (Oralwise, China) of medium brittle hardness and a nylon filament for 2 minutes prior to washing with deionized water. Using $100 \mathrm{mg}$ of each respective toothpaste and at room temperature, it was then brushed (- Table 2). The EB@TiO 2 slurry and toothpaste were set by mixing $100 \mathrm{mg}$

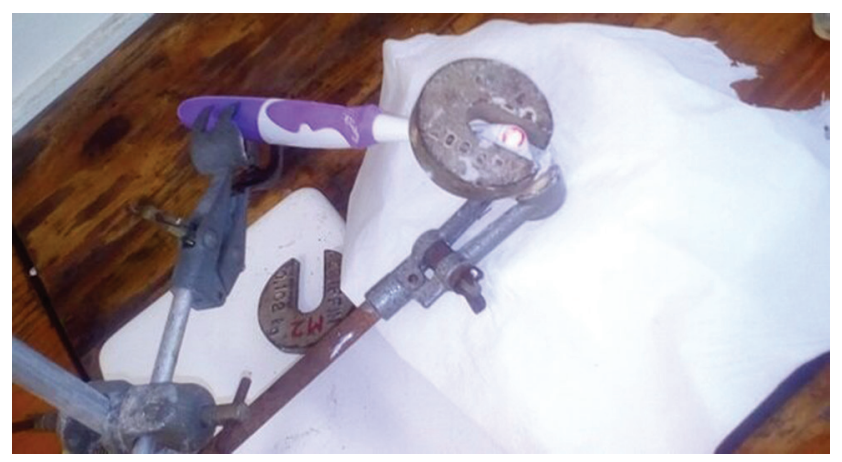

Fig. 1 Brushing protocol apparatus setup.

Table 1 Composition of the prepared artificial saliva ( $\mathrm{mg} / \mathrm{l})$

\begin{tabular}{|l|l|l|}
\hline Chemicals & $\begin{array}{l}\text { Concentration } \\
(\mathbf{m g} / \mathrm{L})\end{array}$ & Mass (g) \\
\hline $\mathrm{NaH}_{2} \mathrm{PO}_{3} \mathrm{H}_{2} \mathrm{O}$ & 780 & 0.078 \\
\hline $\mathrm{NaCl}$ & 500 & 0.05 \\
\hline $\mathrm{KCl}$ & 500 & 0.05 \\
\hline $\mathrm{CaCl}_{2} \mathrm{H}_{2} \mathrm{O}$ & 795 & 0.0795 \\
\hline $\mathrm{NaS}_{9} \mathrm{H}_{2} \mathrm{O}$ & 5 & 0.0005 \\
\hline$\left(\mathrm{NH}_{4}\right)_{2} \mathrm{SO}_{4}$ & 300 & 0.03 \\
\hline $\mathrm{Citric} \mathrm{Acid}$ & 5 & 0.0005 \\
\hline NaHCO & 100 & 0.01 \\
\hline Urea & 1000 & 0.1 \\
\hline
\end{tabular}

of the powder $/ 200 \mu \mathrm{L}$ of deionized water. The protocol load of tooth brushing was $200 \mathrm{~g}$. After the brushing protocol, the tape was subsequently removed.

\section{Atomic Force Microscope (AFM) analysis}

The height differences between the covered halves and the brushed halves of the enamel disc were measured using AFM (Nanoscope; Bruker). The instrument was arranged in contact with a scanning size of $5 \mu \mathrm{m}$ and a scan rate of approximately $2.441 \mathrm{~Hz}$. Five (5) different measurements of the mean surface roughness values for each specimen were done, and average $R_{a}$ values obtained were then used for statistical analysis.

\section{Statistical Analysis}

The mean differences between the brushed and the covered halves of the various sample groups were compared using pairwise tests. In addition, the mean height differences were further compared between all the toothpastes sampled using one-way ANOVA on IBM SPSS v25, supported by Bonferroni correction at $\alpha \square=0.05$ significance level.

\section{Field-Scanning Electron Microscope Observation (FESEM)}

The brushed and covered halves surface of the specimens was characterized by means of a scanning electron microscope (FESEM; Carl Zeiss). As a substitution measure, specimens were analyzed microscopically for each group. The FESEM was operated at controlled atmospheric conditions at $5 \mathrm{kV}$.

\section{Results}

\section{Atomic Force Microscopy (AFM)}

Normality test of the Ra values after brushing is presented in - Table 3. Both the Kolmogorov-Smirnov and the ShapiroWilk test provided no evidence against the normality of the Ra values $(p>.05)$.

The pairwise comparison test of the brushed and covered halves of the tooth (see - Table 4). There is a statistical difference between the brushed and covered halves of the tooth specimens from each of the respective toothpastes $(p<0.05)$. Despite this, the specimens brushed with Colgate toothpaste had the least abrasive $R_{a}$ mean wear gap $(R a=8 \mathrm{~nm})$, followed by EB@TiO ${ }_{2}\left(R_{a}=16 \mathrm{~nm}\right)$. The highest mean wear gap $\left(R_{a}=23\right.$ $\mathrm{nm}$ ) were found in the specimens brushed with Sensodyne rapid relief.

The surface profile of the brushed and covered halves of the specimens is shown AFM micrograph in - Fig. 2. The surface profile evidently reveals the differences between the two halves with the different toothpastes. Notably, the covered halves (A-E) of the specimens appeared rougher than the brushed halves (A1-E1).

The results of the one-way ANOVA, mean, and standard deviation, are given in - Table 5. A statistically significant difference was measured in the mean surface roughness $\mathrm{R}_{\mathrm{a}}$ values of bovine tooth specimens and their interactions with the different toothpastes used for the brushing protocol $(p<0.05)$. Moreover, the mean $\mathrm{R}_{\mathrm{a}}$ values of the bovine 
Table 2 Toothpaste and manufacturers

\begin{tabular}{|l|l|l|l|}
\hline Sample & Abrasive ingredients & RDA value $^{*}$ & Manufacturer \\
\hline Colgate (regular) & $\begin{array}{l}\text { Calcium carbonate, sodium } \\
\text { bicarbonate }\end{array}$ & $68^{29}$ & Colgate-Palmolive \\
\hline Sensodyne rapid relief & $\begin{array}{l}\text { Hydrated silica, pentasodium } \\
\text { triphosphate }\end{array}$ & $70^{14}$ & GlaxoSmithKline \\
\hline Colgate pro-relief & $\begin{array}{l}\text { Pro arginine, calcium carbonate, } \\
\text { sodium bicarbonate }\end{array}$ & 30 & Colgate-Palmolive \\
\hline Sensodyne repair & $\begin{array}{l}\text { Hydrated silica, calcium sodium } \\
\text { phosphosilicate (NovaMIN) }\end{array}$ & $119^{14}$ & GlaxoSmithKline \\
\hline EB@TiO & Eggshells and titanium dioxide & N/A & Researcher (s) \\
\hline
\end{tabular}

Abbreviations: N/A, not applicable; RDA, relative dentin abrasion.

Table 3 Normality test of the surface roughness ( $R a)$ value

\begin{tabular}{|c|c|c|c|c|c|c|c|}
\hline & \multirow[t]{2}{*}{ Group } & \multicolumn{3}{|c|}{ Kolmogorov-Smirnov } & \multicolumn{3}{|c|}{ Shapiro-Wilk } \\
\hline & & Statistic & Df & Sig. & Statistic & Df & Sig. \\
\hline \multirow[t]{5}{*}{ Abrasivity } & Colgate (regular) & .222 & 7 & $.200^{*}$ & .902 & 7 & .346 \\
\hline & Colgate pro-relief & .172 & 7 & $.200^{*}$ & .941 & 7 & .651 \\
\hline & Sensodyne repair & .232 & 7 & $.200^{*}$ & .909 & 7 & .386 \\
\hline & Sensodyne (Sensiform) & .190 & 7 & $.200^{*}$ & .957 & 7 & .795 \\
\hline & $\mathrm{EB} @ \mathrm{TiO}_{2}$ & .273 & 7 & .125 & .879 & 7 & .223 \\
\hline
\end{tabular}

Abbreviation: Df, degree of freedom; Sig., significance.

"Lower bound of the true significance.

aLilliefors significance correction.

Table 4 Paired sample test between the brushed and covered halves

\begin{tabular}{|l|l|l|l|l|}
\hline \multirow{2}{*}{ Sample groups } & \multicolumn{2}{l|}{$\begin{array}{l}\text { Abrasivity } \\
\text { R value }\end{array}$} & \multirow{2}{*}{$\begin{array}{l}\text { Wear } \\
\text { Gap }\end{array}$} \\
\cline { 2 - 4 } & Covered halves & Brushed halves & \\
\hline Colgate & $27.0 \pm 6.2$ & $19.5 \pm 2.6 \mathrm{~nm}$ & $8 \mathrm{~nm}$ & 0.008 \\
\hline Colgate pro-relief & $23.8 \pm 6.6$ & $6.4 \pm 1.0 \mathrm{~nm}$ & $17.4 \mathrm{~nm}$ & 0.001 \\
\hline Sensodyne repair & $29.6 \pm 12.3$ & $7.2 \pm 1.6 \mathrm{~nm}$ & $22.4 \mathrm{~nm}$ & 0.003 \\
\hline Sensodyne rapid relief & $33.5 \pm 6.6$ & $10.5 \pm 2.2 \mathrm{~nm}$ & $23 \mathrm{~nm}$ & 0.000 \\
\hline EB@TiO & $25.6 \pm 5.9$ & $9.6 \pm 3.4 \mathrm{~nm}$ & $16 \mathrm{~nm}$ & 0.002 \\
\hline
\end{tabular}

Abbreviation: Sig., significance.
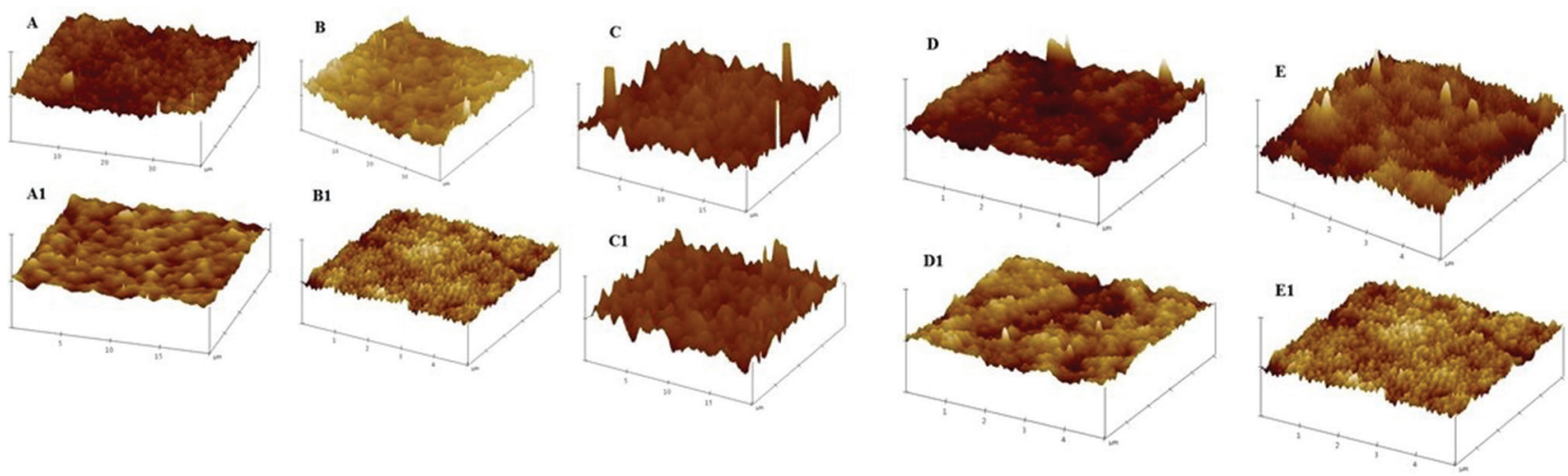

Fig. 2 AFM profile of bovine specimen brushed with (A1) Colgate; (B1) EB@TiO ${ }_{2}$; (C1) Colgate pro-relief; (D1) Sensodyne repair (E1) Sensodyne rapid relief (A-E represents covered halves of the tooth). AFM, atomic force microscope. 
Table 5 Abrasivity of the tested toothpastes

\begin{tabular}{|l|l|l|l|l|l|l|}
\hline Sample groups & N & Mean & SD & SE & ANOVA & $\begin{array}{l}\text { Bonferroni } \\
\text { posthoc test }\end{array}$ \\
\hline Colgate (regular) & 7 & 7.5 & 5.2 & 2.0 & 0.010 & 1.000 \\
\hline Colgate pro-relief & 7 & 17.3 & 7.2 & 2.7 & 0.329 \\
\cline { 1 - 3 } Sensodyne repair & 7 & 22.3 & 12.1 & 4.6 & 0.020 \\
\hline Sensodyne rapid relief & 7 & 23.0 & 6.9 & 2.6 & 0.014 \\
\hline EB@TiO $_{2}$ & 7 & 16.1 & 8.0 & 3.0 & 0.611 \\
\hline
\end{tabular}

Abbreviations: ANOVA, analysis of variance; N, number of specimens; SD, standard deviation; SE, standard error.

specimens brushed with Colgate (regular) were significantly lower than those of the specimens brushed with Sensodyne repair, and Sensodyne rapid relief $(p<0.05)$. There were no statistically significant differences observed between the mean $\mathrm{R}_{\mathrm{a}}$ values of Colgate (regular) and $\mathrm{EB} @ \mathrm{TiO}_{2}$, and Colgate Pro-Relief $(p>0.05)$.

\section{Observation of Specimens Using Field-Scanning Electron Microscope (FESEM)}

The FESEM images of the specimens are shown in - Fig. 3, and the images visibly confirmed the differences in surface roughness between the brushed (A1-E1) and covered halves (A-E) of the specimens and their interaction with differently tested toothpastes. A noticeable difference in the surface roughness of the covered and the brushed halves are evident for all the tested toothpastes.

\section{Discussion}

Dental abrasion from toothpaste abrasives is reported to be a leading cause of a dental problem in the general population. ${ }^{29}$ As a consequence of this, the measurement and standardization of toothpaste abrasives are highly pertinent for the prevention of tooth abrasion. ${ }^{29}$ The study is aimed at evaluating the abrasiveness of an improved/modified nanosized eggshell-titanium dioxide $\left(\mathrm{EB} @ \mathrm{TiO}_{2}\right)$ dental abrasive. Various techniques have been published in the literature to quantify the abrasivity of toothpaste. ${ }^{14,20,30}$ In this study, AFM was used to quantitatively and qualitatively measure the abrasivity of EB@TiO 2 . The mean roughness values $\left(\mathrm{R}_{\mathrm{a}}\right)$ attained were used for statistical analysis. Based on the study results, the tested hypothesis was valid and acceptable. The results show that the different toothpastes used substantially abraded specimens of the tooth enamel $(p<0.05)$.

It further indicated that the $\mathrm{R}_{\mathrm{a}}$ values measured for $\mathrm{EB} @ \mathrm{TiO}_{2}$ were not substantially different from the other toothpastes tested ( $p>0.05)$. Therefore, it can be concluded that EB@TiO, is appropriate for use in toothpaste formulations as a dental abrasive. Although it was reported that by Harris ${ }^{31}$ that $\mathrm{TiO}_{2}$ has a high Mohs hardness and hence abrasive, this study found that $\mathrm{R}_{\mathrm{a}}$ measured for $\mathrm{EB} @ \mathrm{TiO}_{2}$ were comparable with other calcium carbonates containing toothpaste (Colgate regular and Colgate pro-relief). This, therefore, is consistent with the findings by Onwubu et $\mathrm{al}^{24}$ who showed that modifying an eggshell with titanium dioxide has no negative impact on its calcium carbonate structure.
Nonetheless, the $\mathrm{R}_{\mathrm{a}}$ values measured for toothpastes dependent on calcium carbonate (Colgate regular, Colgate pro-relief, and EB@TiO ${ }_{2}$ ) were lower compared with hydrated toothpastes containing silica (Sensodyne repair and Sensodyne rapid relief). The difference in the RDA values, however, could be due to differences determined between toothpastes containing calcium carbonate as the abrasive material and hydrated silica (-Table 2). According to Hunter et $\mathrm{al}^{32}$ while calcium carbonate and hydrated silica is chemically similar, different cleaning/abrasion characteristics can be produced. Other studies ${ }^{33,34}$ are in agreement with this study and observed that calcium carbonate toothpaste showed lower abrasivity when compared against toothpaste containing hydrated silica.

In addition, the results of this study showed that Colgate's daily abrasivity was significantly lower compared with Sensodyne's rapid relief and Sensodyne's repair $(p<0.05)$, respectively. Specifically, the lowest abraded toothpastes measured were found in the specimens brushed with Colgate

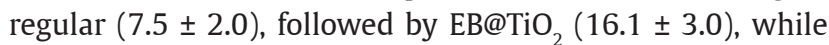
Sensodyne rapid relief had the highest $(23.0 \pm 2.6)$ abraded enamel surface (-Table 5). This finding is in agreement with Schemehorn et al, ${ }^{35}$ who reported that toothpaste having hydrated silica has higher abrasivity on tooth enamel. However, on the other hand, Ferreira et $\mathrm{al}^{36}$ observed no significant difference between calcium carbonate and silica-containing toothpaste. The treatment condition and/or tested toothpaste could be contributors to this difference. For example, Ferreira et $\mathrm{al}^{36}$ acknowledged that the differences observed in the abrasiveness of calcium carbonate and silica were due to the soft surface that is readily abraded, regardless of the abrasiveness found in the toothpaste.

In addition to the above, Hunter et $\mathrm{al}^{32}$ noted that a combination of chemically specific abrasives may have effects that differ from those of the individual component. Arguably, the presence of other active chemicals such as pentasodium triphosphate in Sensodyne rapid relief, and calcium sodium phosphosilicate in Sensodyne repair could have contributed to their increased abrasiveness (-Table 2). Overall, the quantitative results in - Table 4, and the SEM and AFM images (-Figs. 2 and $\mathbf{3}$ ) provide visibly evidence that the brushed and the covered halves (unbrushed) were significantly different. This further supports the work of Athawale at $\mathrm{al}^{37}$ who observed a significant difference in the enamel abrasivity before and after brushing, albeit, with a different toothpaste. Regardless of these findings, in situ studies 

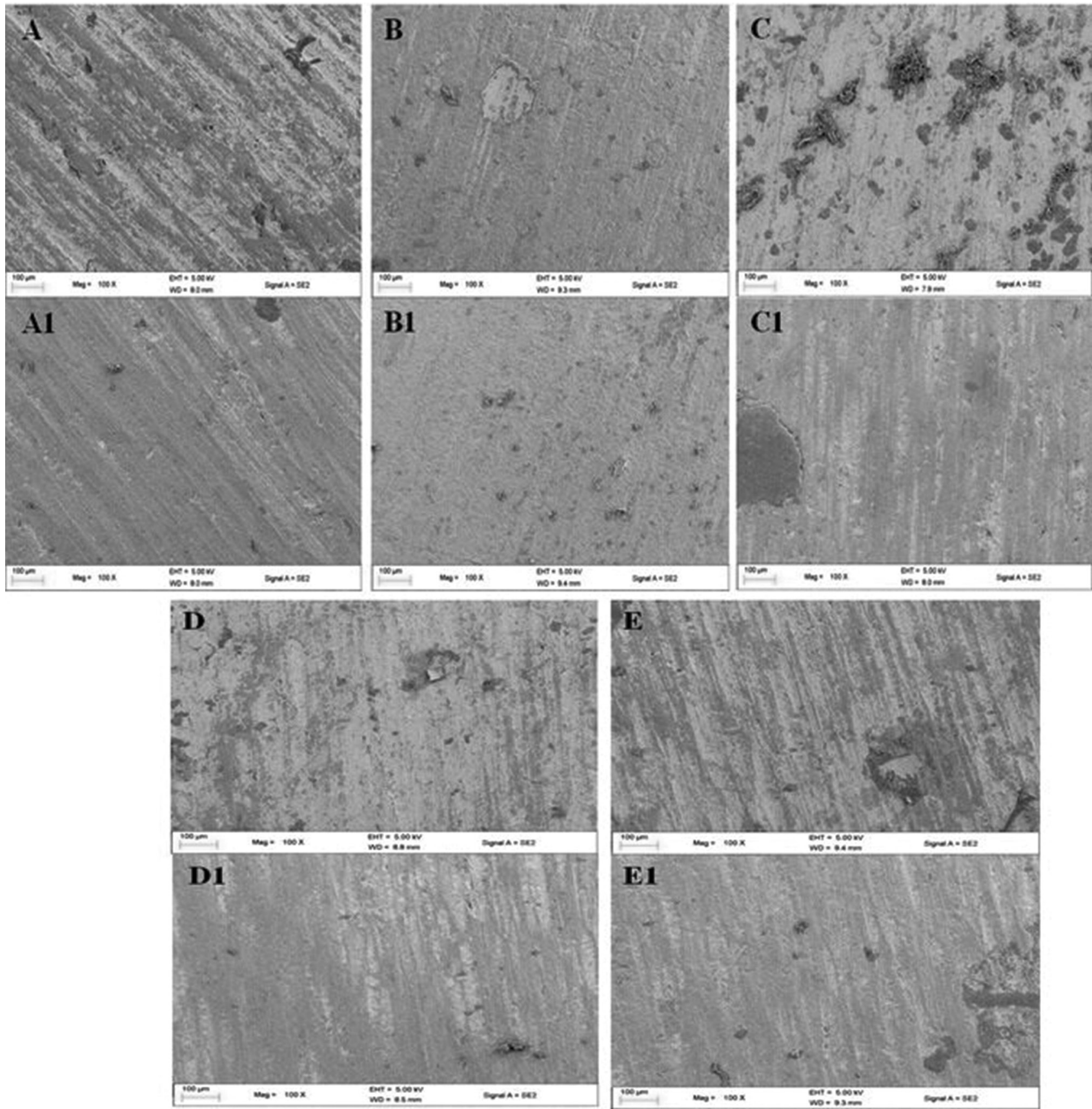

Fig. 3 FESEM images of bovine surface brushed with (A1) Colgate; (B1) EB@TiO ; (C1) Colgate pro-relief; (D1) Sensodyne repair (E1) Sensodyne rapid relief (x100 magnification; A-E represents covered halves of the tooth). FESEM, field-scanning electron microscope.

have shown that the amount of enamel loss from toothpaste abrasion is clinically negligible, ${ }^{38}$ and thus all the different tested toothpastes could be considered safe. Hence, this study conclusively suggests that abrasive material from eggshells would be important in preventing tooth abrasion from toothpaste abrasivity which is considered a dental problem.

Although it has been revealed in the literature that the toothbrush characteristics such as type of brush, filament stiffness, and filament could potentially impact on the tooth enamel, ${ }^{38}$ this present study has only examined the abrasiveness of toothpaste on tooth enamel; the actions of the toothbrush was not investigated. Future study will, therefore, examine the relationship of the toothbrush used and the abrasivity of the toothpaste.

\section{Conclusion}

The prominent aspect of this study reveals that all the tested toothpastes significantly abraded the enamel after brushing. The abrasivity of $\mathrm{EB} @ \mathrm{TiO}_{2}$ was however comparable to the other tested calcium carbonate-containing toothpaste. This

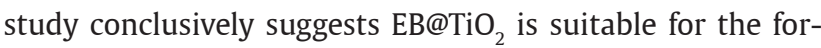
mulation of toothpaste. 


\section{Funding}

This research was funded by the National Research Foundation of South Africa (No. 104824)

\section{Conflict of Interest}

None declared.

\section{References}

1 Abhay S, Dinnimath B, Hullatti K. Formulation and spectral analysis of new polyherbal toothpaste. J Drug Deliv Ther 2014;4(6):68-74

2 Lippert F, An Introduction to Toothpaste-Its Purpose, History and Ingredients. Basel, Switzerland: Toothpastes Karger Publishers; 2013 1-14

3 Addy M, Hunter ML. Can tooth brushing damage your health? Effects on oral and dental tissues. Int Dent J 2003;53(Suppl 3) :177-186

4 Arnold WH, Prange M, Naumova EA. Effectiveness of various toothpastes on dentine tubule occlusion. J Dent 2015;43(4): 440-449

5 Joiner A. Whitening toothpastes: a review of the literature. J Dent 2010;38(Suppl 2) :e17-e24

6 Hara AT, Turssi CP. Baking soda as an abrasive in toothpastes: Mechanism of action and safety and effectiveness considerations. J Am Dent Assoc 2017;148(11S) :S27-S33

7 Giles A, Claydon NC, Addy M, Hughes N, Sufi F, West NX. Clinical in situ study investigating abrasive effects of two commercially available toothpastes. J Oral Rehabil 2009;36(7):498-507

8 Field JC. The investigation of enamel subjected to early erosive and abrasive challenges. Newcastle: University; 2012

9 Absi EG, Addy M, Adams D. Dentine hypersensitivity-the effect of toothbrushing and dietary compounds on dentine in vitro: an SEM study. J Oral Rehabil 1992;19(2):101-110

10 Dyer D, Addy M, Newcombe RG. Studies in vitro of abrasion by different manual toothbrush heads and a standard toothpaste. J Clin Periodontol 2000;27(2):99-103

11 Hara AT, Kelly SA, González-Cabezas C, et al. Influence of fluoride availability of dentifrices on eroded enamel remineralization in situ. Caries Res 2009;43(1):57-63

12 Anusavice KJ, Antonson SA, Materials and processes for cutting, grinding, finishing, and polishing. In: Anusavice KJ, Shen C, Rawls HR, eds. Phillips' Science of Dental Materials. St. Louis: Saunders; 2013236

13 Bizhang M, Riemer K, Arnold WH, Domin J, Zimmer S. Influence of bristle stiffness of manual toothbrushes on eroded and sound human dentin-an in vitro study. PLoS One 2016;11(4): e0153250

14 Arnold WH, Gröger Ch, Bizhang M, Naumova EA. Dentin abrasivity of various desensitizing toothpastes. Head Face Med 2016;12(1):16

15 Addy M. Tooth brushing, tooth wear and dentine hypersensitivity-are they associated? Int Dent J 2005;55(4(Suppl 1) : 261-267

16 Onwubu SC, Vahed A, Singh S, Kanny KM. Physicochemical characterization of a dental eggshell powder abrasive material. J Appl Biomater Funct Mater 2017;15(4):e341-e346

17 International Organization for Standardization, DentistryDentifrices-Requirements, Test Methods and Marking. Geneva, Switzerland: ISO; 2017

18 González-Cabezas C. The chemistry of caries: remineralization and demineralization events with direct clinical relevance. Dent Clin North Am 2010;54(3):469-478
19 Pan H, Tao J, Yu X, et al. Anisotropic demineralization and oriented assembly of hydroxyapatite crystals in enamel: smart structures of biominerals. J Phys Chem B 2008;112(24): 7162-7165

20 Gronwald H, Mitura K, Volesky L, et al. The influence of suspension containing nanodiamonds on the morphology of the tooth tissue surface in atomic force microscope observations. BioMed Res Int 2018;2018:9856851

21 Nayyer M, Zahid S, Hassan SH, et al. Comparative abrasive wear resistance and surface analysis of dental resin-based materials. Eur J Dent 2018;12(1):57-66

22 Bozec L, Horton MA. Skeletal tissues as nanomaterials. J Mater Sci Mater Med 2006;17(11):1043-1048

23 Gaikwad RM, Sokolov I. Silica nanoparticles to polish tooth surfaces for caries prevention. J Dent Res 2008;87(10):980-983

24 Onwubu SC, Mdluli PS, Singh S, Lawrence M, Ngombane Y. Characterization and in vitro evaluation of an acid resistant nanosized dental eggshell-titanium dioxide material. Adv Powder Technol 2019;30(4):766-773

25 Onwubu SC, Mdluli PS, Singh S, Nyembe S, Thakur R, An in situ evaluation of the protective effect of nano eggshell/titanium dioxide against erosive acids. International Journal of Dentistry 2018;2018:4216415

26 Onwubu SC, Mdluli PS, Singh S, Tlapana T. A novel application of nano eggshell/titanium dioxide composite on occluding dentine tubules: an in vitro study. Braz Oral Res 2019;33:e016

27 Onwubu SC, Mdluli PS, Singh S, Bharuth V. Remineralization potential of a modified eggshell-titanium composite-scanning electron microscope study. Eur J Dent 2019;13(2):187-192

28 Onwubu SC, Mdluli PS, Singh S, Bharuth V, Makgobole MU. Evaluation of the occluding characteristics of nanosized eggshell/titanium dioxide with or without saliva. Eur J Dent 2019;13(4):547-555

29 Rath SK, Sharma V, Pratap CB, Chaturvedi TP. Abrasivity of dentrifices: an update. Journal of Research in Dental Sciences. 2016;7(2):96-100

30 Ganss C, Marten J, Hara AT, Schlueter N. Toothpastes and enamel erosion/abrasion - Impact of active ingredients and the particulate fraction. J Dent 2016;54(62-67):62-67

31 Harris RM, A primer on colorful additives. In: Harris RM, ed. Coloring Technology for Plastics. Norwich: Williams and Andrew; 1999

32 Hunter ML, Addy M, Pickles MJ, Joiner A. The role of toothpastes and toothbrushes in the aetiology of tooth wear. Int Dent J 2002;52:399-405

33 Camargo IM, Saiki M, Vasconcellos MB, Avila DM. Abrasiveness evaluation of silica and calcium carbonate used in the production of dentifrices. J Cosmet Sci 2001;52(3):163-167

34 Moore C, Addy M. Wear of dentine in vitro by toothpaste abrasives and detergents alone and combined. J Clin Periodontol 2005;32(12):1242-1246

35 Schemehorn BR, Moore MH, Putt MS. Abrasion, polishing, and stain removal characteristics of various commercial dentifrices in vitro. J Clin Dent 2011;22(1):11-18

36 Ferreira MC, Ramos-Jorge ML, Delbem ACB, Vieirac RdeS. Effect of Toothpastes with Different Abrasives on Eroded Human Enamel: an in situ/ex vivo study. Open Dent J 2013;7:132-139

37 Athawale R, Srinath SK, Chowdary C. Comparative evaluation of enamel abrasivity of different commercially available dentifrices-An in vitro study. Journal of Indian Association of Public Health Dentistry. 2018;16(1):78-82

38 Wiegand A, Schlueter N. The role of oral hygiene: does toothbrushing harm? Monogr Oral Sci 2014;25:215-219 